\title{
Correction to: Effects of dust particles on body weight and some haematological parameters in rats in Maiduguri metropolis, Nigeria
}

\author{
Dauda Yahi ${ }^{1}$ - U. K. Sandabe ${ }^{1}$ S. Sani ${ }^{1}$ - L. O. Aka ${ }^{2}$ V. C. Ikaimase $^{3}$
}

Published online: 17 October 2017

(C) Springer-Verlag London Ltd. 2017

Correction to: Comp Clin Pathol (2016) 25:925-932

https://doi.org/10.1007/s00580-016-2282-5

The original version of this paper unfortunately captured the name of Dr. Yahi incorrectly. It should be Dauda Yahi instead of Y. Dauda in the original paper. The name is now corrected in this paper.

The online version of the original article can be found under https://doi. org/10.1007/s00580-016-2282-5

L. O. Aka

lawrence_aka@yahoo.com

1 Department of Veterinary Physiology, Pharmacology, and Biochemistry, University of Maiduguri, Maiduguri, Nigeria

2 Department of Veterinary Physiology/Pharmacology, University of Nigeria, Nsukka, Enugu, Nigeria

3 College of Medical Sciences, University of Calabar, Calabar, Cross River State, Nigeria 